\title{
Formação de mediadores de leitura: sistematização de duas experiências
}

\author{
Maria Alice Mendes de Oliveira Armelin * \\ Maria Cecília Felix de Godoy*
}

* Centro de Estudos e

Pesquisas em Educação, Cultura e Ação Comunitária (Cenpec)

\section{RESUMO}

O presente artigo busca sistematizar a experiência e a metodologia de dois projetos de formação de mediadores de leitura realizados pelo Cenpec. Desenvolvidos em momentos distintos e a partir de demandas diversas, os projetos mantêm percursos e características próprias, mas partem de uma matriz metodológica comum. No sentido de contribuir para a reflexão entre a relação desses aspectos metodológicos e os resultados obtidos, procuramos apresentar o contexto em que os projetos se situam, um histórico de suas trajetórias, os pressupostos teóricos que os norteiam, as estratégias que têm contribuído para a consecução de suas metas e as circunstâncias que dificultam sua implementação.

PALAVRAS-CHAVE

Formação continuada. Mediação de leitura. Metodologia de formação de mediadores. Formação de leitores 


\section{INTRODUÇÃO}

Desde 2003, com o financiamento de fundações empresariais e o apoio de secretarias municipais de educação, o Cenpec vem desenvolvendo projetos voltados para a leitura. Dois deles serão objeto deste artigo: Entre na roda: leitura na escola e na comunidade (ENR) e Ler: prazer e saber (LPS).

Em ambos, o objetivo principal é a formação de mediadores de leitura capazes de promover o gosto pela leitura e formar leitores entre crianças, adolescentes, jovens e adultos, públicos com os quais esses mediadores costumam atuar - profissional ou voluntariamente - em diferentes espaços.

Tendo como público majoritário educadores de escolas públicas, os projetos desenvolvem oficinas mensais de formação presencial ao longo de um ano (oito oficinas no ENR e dezesseis, no LPS). Nessas oficinas, por meio de atividades diversificadas, trabalha-se com diferentes gêneros textuais de maior circulação social (privilegiando-se aqueles vinculados à literatura). Alternam-se momentos de discussão e reflexão teórica com momentos de vivência de atividades de leitura e compartilhamento de experiências.

Como forma de estimular o trabalho e de oferecer um instrumental que facilite a implementação das propostas, os projetos preveem a entrega de acervos: o ENR para as instituições envolvidas na formação e o LPS para as escolas das redes municipais das cidades beneficiadas pelo projeto. O ENR oferece também aos participantes um material de apoio composto de oito módulos com as concepções que norteiam o projeto, a abordagem de aspectos teóricos, ligados à leitura e aos gêneros discursivos, bem como orientações para o desenvolvimento de atividades de leitura.

Um dos projetos, o LPS, realiza ainda uma premiação em reconhecimento às melhores práticas desenvolvidas pelos educadores, escolas e secretarias municipais de educação.

\section{Contexto EM QUe SE SituAm os PRojetos}

Nas sociedades letradas, qualquer que seja o campo de atuação do indivíduo, a necessidade da leitura e da escrita é cada vez maior. Estamos imersos num universo de mensagens escritas: saber ler e escrever é cada vez mais indispensável para a efetiva inserção do indivíduo na sociedade. Entretanto, por razões históricas e políticas, o Brasil chega ao século XXI com índices que revelam uma grande defasagem em relação ao domínio dessas competências. 
Pesquisas recentes, como RETRATOS DA LEITURA NO BRASIL (2007), revelaram que apenas $55 \%$ da população brasileira (95,6 milhões de pessoas) haviam lido pelo menos um livro nos três meses que antecederam a pesquisa, sendo a média nacional de leitura de 4,7 livros por habitante/ano. Considerando-se somente os livros não indicados pela escola, essa média cai para 1,3 livro por ano, índice inferior ao de países como a Colômbia $(2,4)$ e a França $(7)$.

Partindo dos dados dessa pesquisa, Maria Antonieta da Cunha (2007, p.1314) tece considerações a respeito do acesso à leitura no Brasil. Segundo ela

Os dados [...] confirmam a necessária e estreita relação entre leitura e educação e, objetivamente, com a escola, primeira encarregada da alfabetização e do letramento. Esse vínculo natural torna-se imperativo num país com as desigualdades sociais nos níveis existentes em nosso país, onde a família não exerce o papel de primeira e mais importante definidora do valor da leitura.

Também os dados do Indicador Nacional de Alfabetismo Funcional (INAF, 2009) têm revelado o vínculo entre o maior tempo de escolarização e a melhora nas práticas de leitura e escrita. Em relação a edições anteriores, o Inaf 2009 apresenta uma melhoria nos dados referentes ao alfabetismo funcional, mas, ainda assim, com índices não satisfatórios: entre a população de 15 a 64 anos de zonas urbanas e rurais, 7\% são analfabetos absolutos, isto é, não conseguem realizar tarefas simples que envolvem a leitura de palavras e frases; $21 \%$ têm um nível rudimentar de alfabetismo, isto é, fazem pouco uso da leitura e da escrita na vida diária, demonstrando ter uma compreensão mínima de um texto escrito; 47\% apresentam uma compreensão básica da leitura, sendo capazes de ler e compreender textos de média extensão, localizar informações e realizar pequenas inferências. Somente $25 \%$ atingem níveis mais elevados dessa habilidade e fazem uso mais intenso e diversificado da linguagem escrita: leem textos mais longos, analisando e relacionando suas partes, comparam e avaliam informações, distinguem fato de opinião, realizam inferências e sínteses.

Embora as pesquisas citadas mostrem, ao longo de quase dez anos, uma evolução gradual nos índices de alfabetismo e de leitura, também apontam a necessidade de se continuar e de se aprimorar o trabalho realizado, a partir da soma de esforços entre diferentes segmentos comprometidos com a qualidade da educação e a promoção da leitura. Em consonância com esses dados e atendendo às demandas surgidas nesse movimento de colocar a leitura como um foco prioritário das políticas nacionais de educação e cultura, 
o Cenpec vem desenvolvendo projetos específicos na área de incentivo e formação de leitores como o Entre na roda: leitura na escola e na comunidade e o Ler: prazer e saber.

\section{BREVE HISTÓRICO DOS PROJETOS}

Os projetos abordados neste artigo surgiram em momentos diferentes e a partir de demandas específicas de dois financiadores: a Fundação Volkswagen e o Instituto Camargo Corrêa.

\subsection{ENTRE NA RODA: LEITURA NA ESCOLA E NA COMUNIDADE}

O Entre na roda foi elaborado a pedido da Fundação Volkswagen, que pretendia ampliar sua atuação na área da educação. Foi implementado pela primeira vez em 2003, com o formato de dois anos de duração, em 28 escolas municipais de ensino fundamental de Taubaté, beneficiando 69 educadores.

A partir de então, estendeu-se para escolas municipais da Capital e de municípios do interior de São Paulo, do Rio de Janeiro, de Minas Gerais e ainda para diferentes instituições, graças a parceria estabelecida com a Secretaria de Estado da Cultura de São Paulo (SEC-SP), por meio do programa São Paulo: um estado de leitores.

Essa parceria, iniciada em 2005, levou o projeto a alcançar maior abrangência geográfica e trouxe para as oficinas de formação representantes de outras instituições que não escolas: bibliotecários, responsáveis por salas de leitura implantadas em instituições da capital, entre elas organizações nãogovernamentais, creches, centros de juventude, associações comunitárias, conjuntos habitacionais, escolas de samba e organizações governamentais, tais como Centros de Integração e Cidadania, estabelecimentos prisionais e equipamentos da Secretaria da Saúde, estendendo-se ainda a representantes de 20 comunidades quilombolas do estado. Receber profissionais e voluntários com diferentes perfis e formação diversa significou em parte um desafio (o projeto daria conta de formá-los como mediadores?), em parte uma conquista, em função dos resultados significativos, representados pelas iniciativas desenvolvidas no sentido de tornar os locais de atuação desses mediadores espaços vivos de leitura. ${ }^{1}$

1 A Fundação de Amparo ao Preso, FUNAP, por exemplo, que contava com quatro participantes na turma de 2005/2006, levou as propostas e atividades do Entre na roda para 50 profissionais (monitores orientadores regionais, supervisores regionais e gerentes 
De 2005 a 2008, além da formação in loco (nos municípios) e das turmas da SEC-SP, o ENR desenvolveu a formação em quatro turmas, constituídas, cada uma, de 40 gestores de diferentes secretarias municipais de educação $(n=20)$, em sua maioria do interior de São Paulo, que se reuniam na Capital do estado. O objetivo do trabalho com esses grupos "de representação" era articular com as secretarias ações para a disseminação das propostas do projeto. Alguns municípios optaram por desenvolvê-lo em uma ou duas escolas-piloto e, outros, em todas as escolas da rede, como no caso dos municípios de Cajamar e Várzea Paulista.

A partir de 2009, o formato do projeto se modifica, reduz-se o número de oficinas e a duração da formação passa a ser de um ano. Isso traz para o projeto a necessidade de outros arranjos na constituição dos grupos de formação, de modo a tentar garantir uma maior sustentação na implementação das propostas e sua continuidade nos municípios após a conclusão da formação dada pelo projeto. Assim, como alternativa à participação de um representante por instituição (professor, coordenador pedagógico, diretor, técnico de secretaria, bibliotecário, agente social, voluntário, etc.) que ocorreu até 2008, tanto as turmas in loco quanto as de representação passaram, em geral, a se organizar em torno de grupos de educadores (basicamente dois professores e um coordenador pedagógico ou diretor por escola), acompanhados de um técnico da secretaria municipal de educação.

Em decorrência dessa redução do tempo de formação, perdeu-se a possibilidade de aprofundar conhecimentos teóricos, de ampliar a diversidade de gêneros enfocados e de acompanhar o movimento que ia da apropriação das práticas de trabalho com a leitura e disseminação do projeto - que ocorriam já no 1 ํ ano de formação - até um “enraizamento” maior deste, que ocorria no $2^{\circ}$ ano.

Por outro lado, o fato de se passar a contar com a formação simultânea de educadores e coordenadores das mesmas escolas permitiu que o trabalho de disseminação do projeto nas escolas assumisse um caráter mais coletivo.

Até o presente momento, o ENR formou 4.593 mediadores de leitura, representando 1.901 instituições de 244 municípios de três estados: São Paulo, Minas Gerais e Rio de Janeiro.

Ao longo dos encontros de formação realizados a cada ano, as notícias da

regionais), os quais se encarregaram de disseminá-las para outros 300 educadores, beneficiando com rodas de leitura (mais à frente se caracterizam as rodas de leitura) e outras atividades 13.307 alunos em unidades prisionais do estado. 
disseminação das propostas do ENR e do sucesso das rodas de leitura² nos chegam pelo relato verbal, pelo registro escrito e fotográfico realizado pelos participantes, pelas matérias publicadas em jornais e sites locais e pelas fotos e relatos postados na Comunidade Virtual do Programa Território Escola ${ }^{3}$, no qual se insere o projeto.

\subsection{LER: PRAZER E SABER}

O projeto Ler: prazer e saber foi idealizado para atender a uma demanda do Instituto Camargo Corrêa: formar mediadores de leitura entre os educadores de escolas públicas de municípios onde estão instaladas unidades vinculadas ao grupo Camargo Corrêa.

O Instituto desenvolve diversas ações junto aos municípios que atende, entre elas o Programa Escola Ideal, cujo foco reside na melhoria da gestão da escola pública. Entre os diagnósticos realizados para fundamentar as ações, um deles apontou para a necessidade de recursos pedagógicos, revitalização e atualização das bibliotecas escolares e oportunidades de formação continuada e aperfeiçoamento pedagógica para os educadores. Entre as prioridades destacadas estava o trabalho com a leitura. Daí a demanda por um projeto que pudesse proporcionar a conservação e o uso dos acervos entregues pelo próprio Instituto e a mobilização em torno do incentivo a práticas de leitura mais ricas, diversificadas e permanentes envolvendo a escola, a comunidade e o poder público.

A primeira experiência com a implementação do projeto foi realizada a partir do segundo semestre de 2009 em seis municípios da Paraíba: Alagoa Nova, Campina Grande, Guarabira, Ingá, Mogeiro e Serra Redonda. Com exceção, evidentemente, de Campina Grande; os demais municípios são de pequeno e médio porte. As escolas que participaram do projeto, também à exceção das de Campina Grande, estão em sua maioria concentradas na área rural dos seis municípios.

Após 16 oficinas de formação continuada, visitas de acompanhamento às escolas e reuniões com as secretarias dos municípios, o projeto fechou 2010

2 Como se verá mais à frente, as rodas de leitura são momentos em que pessoas se reúnem para ouvir, ler e comentar textos de diferentes gêneros.

3 O Programa Território Escola é constituído por quatro projetos voltados para o ensino básico: "Brincar: o brinquedo e a brincadeira na infância”, "Aceleração de Aprendizagem”, "Entre na roda: leitura na escola e na comunidade" e "Estudar pra valer! leitura e produção de texto no ensino fundamental".Trata-se de uma iniciativa da Fundação Volkswagen, desenvolvida sob a coordenação técnica do Cenpec. 
com a Jornada de Práticas Exemplares, que reconheceu e premiou o trabalho desenvolvido pelas secretarias, escolas e, principalmente, pelos educadores que se apropriaram das propostas do projeto e as desenvolveram com seus alunos, socializaram-nas com seus pares e saíram dos muros das escolas para levar e incentivar a leitura entre pais e comunidade.

Neste ano, outros municípios estão sendo atendidos pelo projeto: Apiaí e Itaoca, no estado de São Paulo, Guajará Mirim e Porto Velho, no estado de Rondônia, e ljaci, Pedro Leopoldo e Santana do Paraíso, em Minas Gerais.

Pelo trabalho desenvolvido nos seis municípios da Paraíba e os resultados alcançados, o projeto recebeu no início de novembro deste ano a Menção Honrosa do Prêmio Vivaleitura 2011, uma iniciativa do Ministério da Educação e Ministério da Cultura, da Organização dos Estados Ibero-americanos para a Educação, a Ciência e a Cultura (OEI) e da Fundação Santillana, com o apoio do CONSED (Conselho Nacional de Secretário de Educação) e da UNDIME (União Nacional do Dirigentes Municipais e Educação).

\section{PRESSUPOSTOS QUE NORTEIAM OS PROJETOS}

Os dois projetos se organizam a partir de uma matriz metodológica comum e têm como pressupostos que orientam suas ações: uma concepção de leitura e, portanto, de linguagem; o reconhecimento da importância do mediador na formação de leitores e uma determinada compreensão do processo de formação do leitor.

\section{1 CONCEPÇÃO DE LEITURA}

Consideramos, evidentemente, que a leitura não se refere ao simples ato de decifrar o código escrito, nem de apenas saber localizar e repetir conteúdos específicos de um texto, de forma linear e literal. É importante destacar essa ideia, pois durante muito tempo se acreditou que bastava estar alfabetizado ou ser capaz de repetir o que estava escrito para se compreender qualquer texto. Hoje sabemos que um leitor proficiente é aquele que sabe utilizar procedimentos de leitura, de modo a reconstruir os sentidos do texto, dialogar com ele, concordar, discordar, etc.

Um texto é sempre o resultado das experiências do autor à época de sua produção, isto é, de sua maneira de ver o mundo, de suas expectativas, crenças, valores, dos conhecimentos de que dispunha naquele momento, das influências que recebeu.

A leitura desse texto também é fruto das experiências e conhecimentos de 
que dispõe o leitor, no momento histórico em que ocorre a leitura. Portanto, nem sempre ao sentido pretendido pelo autor correspondem os sentidos atribuídos por seus possíveis leitores, ainda que autor e leitores dominem uma mesma língua e vivam num mesmo tempo.

Ler, portanto, não é um processo linear e um mesmo texto possibilita diferentes leituras, ainda que lido por pessoas que compartilhem um mesmo momento histórico. Por mais modeladas que sejam as várias formas de discurso, a história de leitura de cada um está presente na sua manifestação individual, fazendo parte da história de leitura do mundo.

Ao interagir verbalmente com o outro, o discurso do locutor se organiza a partir de finalidades e intenções, tendo como referência o seu interlocutor e o tema da interlocução. Isso significa que aquilo que o sujeito pressupõe sobre seu interlocutor - conhecimentos, crenças/valores, opiniões, convicções, simpatias e antipatias - , além do grau de afinidade e familiaridade que ambos têm e da posição social e hierárquica que ocupam, interferem na interlocução.

Vale assinalar aqui que o discurso, quando produzido, manifestase linguisticamente por meio de gêneros orais ou escritos, motivados justamente por esses condicionantes. Segundo Bakhtin (1990, 1992), os textos que produzimos, orais ou escritos, são formas de dizer que se originam das necessidades criadas em diferentes esferas da comunicação humana. Essas formas de dizer (oralmente ou por escrito) não são inventadas a cada vez que nos comunicamos, mas estão à nossa disposição, circulam nos diferentes meios sociais, tenhamos ou não consciência delas. Quando nos comunicamos, nas mais diversas situações, utilizamos essas formas, que possuem características próprias e relativamente estáveis. Essas características configuram diferentes gêneros discursivos que podem ser definidos por três aspectos básicos coexistentes: seus temas (o que é dizível ou pode se tornar dizível, por meio do gênero), sua construção composicional (forma particular dos textos pertencentes ao gênero) e seu estilo (seleção feita pelo autor de recursos da língua - de vocabulário e gramaticais -, tendo em vista o gênero).

Gêneros são, portanto, formas de enunciados produzidos historicamente, que se encontram disponíveis na cultura. Fazemos uso de gêneros discursivos que nos foram transmitidos histórica e socialmente, o que não quer dizer que não seja possível transformar esses gêneros, ou que outros não sejam criados de acordo com as novas necessidades culturais de interação verbal 
que surgem historicamente.

O contato com os diversos gêneros discursivos que circulam socialmente entre nós não somente amplia as capacidades linguísticas e discursivas dos leitores, mas também lhes aponta inúmeras formas de participação social que eles podem ter como cidadãos, usando a linguagem.

O gênero discursivo é um instrumento com o qual é possível exercer uma ação linguística sobre a realidade, ampliando as capacidades do usuário e o próprio conhecimento sobre o gênero. ${ }^{4}$

\section{2 A IMPORTÂNCIA DA MEDIAÇÃO NA FORMAÇÃO DE LEITORES}

Quando se fala de mediação, toca-se num conceito fundamental para a compreensão da concepção a respeito do desenvolvimento humano como um processo sócio-histórico defendida por Vygotsky (1991). Segundo ele, a interação entre indivíduos mais experientes e outros, menos experientes, torna possível aos sujeitos constituírem-se como tal e construírem conhecimentos. Em função disso, pode-se entender a importância da atuação dos membros do grupo social na mediação entre cultura e indivíduo e também a relevância da escola, local onde a intervenção pedagógica desencadeia o processo de ensino-aprendizagem que promove o desenvolvimento do aluno. Nesse processo, o professor tem como tarefa ajudar o aluno a alcançar um desenvolvimento que ele ainda não consegue atingir sozinho.

Pensando no caso específico da leitura, para além do professor, o trabalho de mediação pode e deve ser exercido também por leitores mais experientes - familiares, amigos, bibliotecários, ou colegas mais capazes - que possam fazer avançar aquele que ainda não lê ou o faz com dificuldade, para que, gradativamente adquira proficiência e conquiste autonomia.

Sabemos que para formar leitores não basta colocar as pessoas em contato com materiais escritos, embora essa seja a primeira condição. É preciso incentivá-las a fazer descobertas e ajudá-las a realizar escolhas, a compreender textos mais complexos, a avançar na formação do gosto - tarefas inerentes ao trabalho do mediador de leitura.

Enquanto leitor mais experiente, o mediador poderá ajudar os novos leitores a se interessar pelo imenso patrimônio cultural, acumulado ao longo da história

Sobre a relação entre a concepção de gênero discursivo e sua aplicação nos projetos, ver item 5.3 deste artigo. 
da humanidade, mas que nem todos conseguem usufruir em igualdade de condições.

Orientando, apoiando e incentivando os leitores em formação, o mediador poderá levá-los a ampliar seu repertório; a conhecer novos mundos, culturas e civilizações diferentes; poderá gerar condições favoráveis para que consigam articular informações e mostrar que ler e escrever, além de promover socialmente e dar acesso à cultura e ao conhecimento, permitem relacionar a vida de cada um com a realidade na qual se vive. ${ }^{5}$

\subsection{A FORMAÇÃO DO LEITOR}

O processo de formação do leitor é longo e ocorre pela mediação de leitores mais experientes e pela interação com diferentes suportes e gêneros discursivos. Muito antes de ser capaz de compreender o funcionamento do sistema alfabético, o sujeito imerso numa sociedade letrada busca entender o que significam os escritos presentes no mundo em que vive e pode entrar no mundo da escrita pela mão, pelo olhar e pela voz de outras pessoas. Todas as tentativas que ele faz para atribuir sentido a um texto são leituras. Nesse sentido, mesmo os não alfabetizados são capazes de ler, apoiados em ilustrações e em outras marcas do texto, bem como em sua memória.

Para alguns, essa experiência começa muito antes de entrar na escola, quando presenciam atos de leitura praticados pelas pessoas que os rodeiam ou participam deles. Entretanto, muitos dependem exclusivamente da escola para se tornar leitores. Assim, na escola e em outros espaços de aprendizagem, é preciso criar momentos ou situações para que os leitores iniciantes construam e ampliem experiências de leitura, oferecendo-lhes diferentes suportes e gêneros discursivos, lendo para eles com frequência, colocando-os no papel de leitores.

O contato com diferentes suportes e textos e com leitores mais experientes é fundamental para desenvolver o gosto pela leitura e formar leitores competentes. Essa competência - que se forma com o manuseio e a leitura de muitos suportes e textos - inclui saberes diversos.

No que se refere ao livro, por exemplo, saber segurá-lo e manuseá-lo corretamente; saber que a capa apresenta em geral o nome do autor, o título do livro e a editora; perceber que livros com muitas histórias ou

Esse aspecto está detalhado no item 5.4.1 deste artigo 
poemas comumente trazem um índice; descobrir que no verso da folha de rosto há uma ficha catalográfica com informações sobre a edição da obra; e, principalmente, reconhecer obras de boa qualidade, apontar autores e ilustradores que admira e comentar um texto lido, justificando suas opiniões, sem contar os modos de "sentir" a realidade física do material escrito que vão do olhar ao toque, do olfato ao próprio poder gustativo imaginário ou não, tornando o livro um particular "fetiche".

Se o suporte de leitura for um jornal, saber como se organiza a primeira página, como se localizam as notícias dentro do jornal, qual é a diferença entre um editorial, um artigo de opinião assinado e uma reportagem; descobrir a função das manchetes; ser capaz de comparar diferentes jornais são também conhecimentos fundamentais.

Já a leitura de uma propaganda requer outras capacidades, como relacionar a mensagem escrita com a imagem, compreender a linguagem figurada, etc.

Por sua vez, a leitura realizada em ambiente digital, exige do leitor capacidades bem específicas, entre elas, a de definir o trajeto de sua leitura pelas janelas dos hipertextos e a de selecionar as informações de que necessita, checando sua autenticidade, por exemplo. ${ }^{6}$

\subsubsection{A IMPORTÂNCIA DA LITERATURA NA FORMAÇÃO DE LEITORES}

Quando se fala da formação de leitores, não se deve esquecer a contribuição que a literatura pode trazer a esse processo.

Aliteratura é matéria privilegiada para motivare formarleitores, porser linguagem que se oferece a múltiplas interpretações. Ela funde harmoniosamente realidade e fantasia - sendo um material inestimável na formação do indivíduo em sociedade -, toca primeiro a emoção e depois leva à reflexão, à análise, à interpretação e até mesmo à produção de outros textos.

Por essa especificidade, na formação do leitor, ambos os projetos dão especial destaque aos gêneros vinculados à literatura, tentando aproximar conhecimento e prazer, casamento esse que nem sempre faz parte do cotidiano das escolas e de outros espaços de aprendizagem. Comumente

6 A leitura em ambiente digital não é foco de trabalho dos projetos ENR e LPS. Todavia, ao longo das oficinas, os participantes são orientados a utilizar a internet para ampliar seus conhecimentos a respeito de obras e autores. São indicados sites dos próprios autores e outros reconhecidamente confiáveis como fonte de pesquisa. Sobre o trabalho com diferentes suportes nos Projetos, ver o item 5.3 deste artigo. 
a leitura de fruição é proposta na escola como uma atividade menor, para ocupar o tempo: depois que os alunos acabaram de fazer atividades "sérias", podem pegar livros para ler, até que todos terminem as tarefas.

O texto literário é matéria criativa e "reveladora", capaz de inquietar prazerosamente os educadores para o gosto da leitura, experiência essa que naturalmente eles podem promover junto aos alunos e à comunidade, acentuando que a leitura de textos literários permeia todas as formas de conhecimento: a literatura está sempre voltada para a condição humana e a serviço da vida.

Por isso, um primeiro passo para desenvolver o gosto dos leitores iniciantes é colocá-los em contato com muitos textos de boa qualidade, com um acervo contendo diversidade de gêneros, temas, autores, ilustradores, estilos, tratamento gráfico, para atender às expectativas mais variadas.

Identificar uma obra como sendo de boa qualidade significa também levar em conta os valores estéticos da obra (linguagem criativa, sugestiva, fluente, temas interessantes ou intrigantes, inventividade no jogo das palavras, potencial lúdico e outros), o respaldo da crítica e, sobretudo, a receptividade dos leitores a quem a obra se destina.

Livros bons, em geral, tornam-se inesquecíveis, porque a cada releitura têm sempre algo a nos dizer. Permitem a quem os lê viver simbolicamente outras vidas, com experiências diferentes do seu cotidiano. Despertam no leitor o gosto pela exploração da diversidade e pelo conhecimento do outro; possibilitam-lhe reconhecer-se nos personagens e, pelo distanciamento da ficção, compreender melhor as próprias experiências.

Quando o mediador oferece bons livros a crianças, jovens e adultos, seu papel de formador de leitores já está parcialmente cumprido, porque as múltiplas experiências de leitura, sobretudo aquelas que são críticas e prazerosas, depuram o gosto.

Apesar do foco sobre os textos literários, a familiaridade com outros gêneros discursivos, que circulam numa sociedade letrada, também é fundamental para a formação do leitor, tendo em vista que a todo o momento ele é solicitado a ler com diferentes finalidades, para fazer frente a todos os desafios que a vida moderna lhe impõe. Por isso é recomendável que, ao trabalhar com a leitura, o mediador aborde, por exemplo, os textos jornalísticos, nos quais o leitor pode encontrar, sobretudo, informação e reflexão sobre os acontecimentos que interferem diretamente em sua vida. Da mesma forma, o trabalho com textos de divulgação científica aproxima o leitor do conhecimento produzido em várias áreas do saber. 
Contudo, qualquer que seja o gênero abordado, é importante oferecer atividades que tenham como principal finalidade a fruição e a reflexão.

\section{MetOdologia dos PROJetOS}

Como já foi dito anteriormente, embora o ENR e o LPS tenham surgido em momentos distintos e a partir de demandas diferentes, ambos têm uma grande proximidade no que diz respeito aos objetivos e resultados atingidos. Isso se deve, sobretudo, à opção por uma metodologia centrada nos pressupostos já abordados e construída a partir da experiência do Cenpec no trabalho com a formação de educadores.

Abordaremos a seguir alguns aspectos que fazem parte dessa metodologia e que consideramos terem sido essenciais para a consecução de resultados significativos na formação de mediadores de leitura, obtidos pelos dois projetos.

\section{1 DIÁLOGO ENTRE TEORIA E PRÁTICA}

Nos dois projetos a formação desenvolve-se por meio de oficinas presenciais. Nelas, mesclam-se momentos de apresentação e discussão de aspectos teóricos envolvendo a leitura e os gêneros discursivos trabalhados, a vivência de atividades que busca colocar esses conhecimentos na prática e a discussão da própria prática, num movimento de ação-reflexão-ação.

Daí a importância de que as oficinas se realizem com um espaço de tempo entre elas, o que permite ao mediador em formação experimentar com seu público o que ele próprio vivenciou, refletir sobre o que realizou, de que maneira o fez e sobre os resultados de seu trabalho. Essas observações são levadas para a oficina seguinte, de modo a socializar no grupo os êxitos e as dificuldades. Uma vez compartilhados, os êxitos vão inspirar e motivar novas experiências por parte do grupo e as dificuldades tornam-se objeto de reflexão coletiva. As múltiplas experiências vividas por cada um e socializadas nesse espaço de trocas, que são as oficinas, contribuem para delinear possíveis soluções, já que as dificuldades - sejam elas inerentes à atuação do mediador em sala de aula/ em outros espaços, sejam ligadas a questões externas que afetam a realização do trabalho com leitura (falta de infraestrutura, falta de apoio dos gestores, resistência dos colegas etc.) - nem sempre são individuais.

Vale destacar aqui a importância dos formadores no sentido de acolher, orientar e respaldar o trabalho dos mediadores em formação. Deve-se 
creditar à competência e à sólida experiência desses formadores parte dos bons resultados que os dois projetos vêm obtendo ao longo de sua trajetória.

\section{2 A VALORIZAÇÃO DA ESCUTA E DA TROCA}

A formação presencial permite a criação de vínculos consistentes que, ao longo do tempo, vão se construindo na relação entre o formador e os participantes e entre estes e seus pares. Procura-se valorizar a escuta como estratégia que possibilita a aprendizagem, a troca e a construção do conhecimento. Dar voz ao outro, num clima de respeito e acolhimento, gera confiança, aumenta a autoestima e permite a construção de espaços em que todos se sentem à vontade para expor dúvidas, discutir idéias e problemas e buscar, coletivamente, soluções.

Para além do espaço físico em que mensalmente os mediadores em formação se encontram, o espaço virtual também oferece a possibilidade de dar continuidade às trocas. Os participantes do ENR dispõem de um espaço de comunicação a distância, para divulgação de notícias, textos voltados para a questão da leitura, troca de informações, postagem de fotos e de relatos referentes ao desenvolvimento do projeto em seus locais de trabalho. Tratase da Comunidade Virtual de Aprendizagem do Programa Território Escola ${ }^{7}$ no qual se insere o ENR. O material ali postado pelos participantes permite conhecer algumas das práticas desenvolvidas a partir da formação continuada oferecida pelo projeto.

\section{3 DiVERSIDADE DE GÊNEROS E SUPORTES}

Ao longo das oficinas dos projetos em questão, propomos atividades em que são explorados diferentes gêneros discursivos - histórias da tradição oral (“causos", contos de encantamento, lendas, fábulas), crônicas, memórias, contos, romance, novela, texto teatral, poemas, textos jornalísticos, textos de divulgação científica.

Em cada uma delas, observamos e comentamos aspectos discursivos (condições de produção) e formais (estrutura textual, recursos linguísticos e expressivos), bem como procuramos orientar para que se identifiquem dificuldades de leitura que o texto possa acarretar, sejam relativas ao contexto de produção, sejam referentes a conteúdos semânticos e sintáticos.

Para acessar: http://www.territorioescola.org.br. 
Privilegiamos os gêneros discursivos ligados à literatura, mas abordamos também os textos jornalísticos e de divulgação científica, menos voltados para o entretenimento e mais para a informação. Com isso, busca-se reafirmar que para além do prazer, a leitura traz também o conhecimento (o que também pode ser prazeroso). A seleção desses gêneros vincula-se à sua circulação social, à proximidade com o universo dos participantes (ex: tradição oral) e à adequação para um trabalho com leitura, contação etc. - atividades propostas pelo projeto.

Nas oficinas de formação, destacamos o trabalho com a caracterização dos gêneros e informações sobre sua origem e transformações ao longo do tempo - não muito aprofundado, mas que permite reconhecer obras do mesmo gênero e apreciá-las melhor, tendo em vista a forma como essas características se realizam em cada texto, a partir da obra e do estilo de cada autor.

Procuramos mostraro contexto de produção das obras. Durante o planejamento das atividades desenvolvidas na formação, são selecionados pela equipe de formadores dos projetos textos/autores significativos, sobretudo da literatura brasileira; nas oficinas são trabalhados textos de autores clássicos e contemporâneos, o que permite também destacar a evolução do gênero e a riqueza de estilos. Isso traz para o participante da formação uma ampliação de repertório - conhecimento de maior número de obras e autores - e um refinamento do olhar para avaliar com mais propriedade os textos que pode/ deve levar para as rodas de leitura que vai realizar com seu público. Atividades como as rodas de empréstimo e de apreciação sobre as leituras realizadas, propostas pelos projetos e vivenciadas nas oficinas, mobilizam os educadores a ler textos que, gradativamente, exigem mais deles como leitores. Exemplo disso são os gêneros de estrutura mais complexa, como o romance; gêneros que circulam menos entre os leitores, como o texto dramático; autores clássicos ou modernos tidos por esse público como de difícil leitura, por exemplo, Machado de Assis, Guimarães Rosa, etc. O estímulo ao contato com gêneros, obras e autores com os quais muitas vezes não tinham intimidade, traz, como resultado claramente observável, um crescimento pessoal desses participantes como leitores.

Quanto aos suportes, o livro sem dúvida, ocupa um papel de destaque em ambos os projetos, tanto que paralelamente à formação dos mediadores, acervos de livros, sobretudo de literatura, são doados ${ }^{8}$ a escolas e a outras

8 Os acervos doados pelo Instituto Camargo Corrêa (no caso do LPS) variam de 50 a 200 títulos selecionados pela Associação Rio-Grandense de Bibliotecários (Projeto PróBiblioteca). Incluem obras de literatura infanto-juvenil, obras de referência, quadrinhos 
instituições. Mas o trabalho com textos jornalísticos e de divulgação científica enseja o manuseio de portadores como jornais, revistas, folhetos etc. Já a busca por autores e textos de diferentes gêneros não pode prescindir também do ambiente virtual, suporte privilegiado, onde circulam informações, críticas, resenhas, imagens, trechos de obras e onde até mesmo obras completas são disponibilizadas para download.

\section{4 ATIVIDAdeS DE LEITURA DIVERSIFICADAS}

Entre as atividades propostas pelos projetos e vivenciadas nas oficinas de formação estão principalmente as rodas de leitura, de apreciação e de empréstimo.

\section{4. 1 RODAS DE LEITURA}

As rodas de leitura remetem à tradição das leituras públicas: um leitor apresenta para um grupo de ouvintes uma obra ou trechos de uma obra, por meio de uma leitura fluente e expressiva ou, ocasionalmente, por meio de contação. No caso dos dois projetos, o preparo e realização de rodas de leitura pressupõem o uso de algumas estratégias. Vivenciadas pelos participantes nas oficinas formação, elas passam gradualmente a fazer parte de sua prática ao planejar e realizar rodas de leitura com seu público.

Fazem parte desse conjunto de estratégias, e são recomendadas pelos dois projetos, algumas ações que devem ocorrer antes, durante e após a leitura, a saber:

Antes da leitura:

- Escolher textos de boa qualidade; adequados à faixa etária do público.

- Preparar-se para o momento da apresentação, estudando o texto antes, observando aspectos relevantes e antecipando possíveis dúvidas ou comentários.

e paradidáticos entregues a todas as escolas das redes dos municípios atendidos, independentemente da participação de seus representantes na formação. Acompanha esse acervo uma estante móvel que facilita a exposição dos livros e a circulação do acervo pelas salas de aula. Já os acervos doados pela Fundação Volkswagen(no caso do ENR) contêm 100 títulos selecionados pela equipe do próprio projeto (Cenpec). Incluem, sobretudo, obras de diferentes gêneros vinculados à literatura infanto-juvenil e também obras de caráter informativo. São entregues somente às instituições com representação nas oficinas de formação. 
- Procurar criar um clima de envolvimento. Sempre que possível, pedir aos participantes que se sentem em círculo.

- Dizer o nome do(a) autor(a) da obra apresentada e perguntar aos ouvintes se já o(a) conhecem, se já leram algum livro ou texto dele(a).

- Falar sobre a época e o lugar em que o texto foi escrito.

- Tendo a obra em mãos, mostrar a capa e perguntar se o público imagina o assunto ou tema do texto.

- Apontar o título do livro, e, se necessário, indicar que a orelha e o texto da contracapa tratam resumidamente do tema. Se o livro contiver muitos textos, mostrar ao público como localizar o que ler pelo índice, ou simplesmente deixar o livro sobre a mesa para aguçar a curiosidade.

\section{Durante a leitura:}

- Utilizar recursos para manter ou resgatar a atenção. No caso de uma narrativa, por exemplo, fazer algum tipo de suspense e perguntar: 0 que será que vai acontecer agora? Como o personagem $X$ vai se livrar da enrascada em que se meteu?

- Fazer breves interrupções se notar que a compreensão está difícil, dando algumas pistas para ajudar, mas sem se alongar em explicações, evitando fragmentar a narrativa.

- Se os participantes interromperem com perguntas, responder o necessário e retomar o texto.

Após a leitura:

- Percebendo que os ouvintes não conseguiram compreender bem o texto apresentado, ajudá-los dando pistas, fazendo perguntas e respondendo às deles.

- Oralmente, recuperar com os ouvintes passagens marcantes ou aquelas que causaram entraves à compreensão.

- Estimular comentários e discussões a respeito do tema, das características e atitudes dos personagens, dos usos e costumes de outras épocas e povos.

- Desafiar os ouvintes a ir além do texto, relacionando-o com as próprias experiências. 
- Incentivá-los a exercitar a imaginação, o raciocínio lógico e a coerência, questionando sobre o que aconteceria se determinado fato fosse alterado: E se Fulano tivesse agido assim? O que mudaria na história se Beltrano tivesse respondido...? O que havia por trás da atitude do personagem $Y$ ?

- Chamar a atenção para: o estilo do(a) autor(a), os recursos que ele(a) utiliza para prender a atenção do leitor, a riqueza de expressões, as frases bem construídas, as expressões regionais, gírias, linguagem figurada etc.

- Incentivar os ouvintes a manifestar seus sentimentos e opiniões e ajudálos a ir além do "é legal” ou do "gostei”, pedindo que justifiquem suas opiniões sobre a história, as ilustrações, o estilo do(a) autor(a) - o jeito de contar/escrever - etc.

- Estimular a reflexão, a partir do(s) ponto(s) de vista do(a) autor(a) do texto, abrindo perspectivas para a discussão de situações reais e a busca de soluções de problemas, sejam individuais ou coletivos.

- Criar também situações em que os próprios participantes da roda de leitura escolham livros para ler, sejam alfabetizados ou não. A leitura livre deve se tornar uma prática no grupo. Todos podem e devem ler, ainda que não o façam convencionalmente. Nesse sentido é interessante organizar estratégias que possibilitem aos leitores mais experientes auxiliar os menos experientes.

\section{4. 2 RODAS DE APRECIAÇÃO}

Em todas as oficinas os participantes da formação são orientados a disponibilizar obras que possuem, que já leram e que gostariam de compartilhar com outras pessoas do grupo. Fazem, ainda, oralmente ou por escrito, a indicação dessa obra, destacando por que a recomendam.

As rodas de apreciação cumprem, assim, o objetivo de estimular no grupo a troca de informações e comentários críticos sobre autores e obras lidas espontaneamente. Os comentários e a recomendação de obras funcionam como motivador para que outros leitores se interessem por elas e desejem lê-las. 
Fechando essa tríade de atividades básicas, vem o empréstimo que, como vimos acima, está intimamente ligado às rodas de apreciação. Estimulase o empréstimo, para levar os mediadores em formação a uma ampliação de repertório e a uma maior proficiência na leitura. Orienta-se para que essa atividade seja replicada nos espaços em que eles atuam após a roda de leitura, por exemplo, para promover entre os leitores a circulação de um gênero, autor ou portador que acabou de ser apresentado ou conhecido. Ou, ainda, em determinados momentos da rotina estabelecida entre o mediador e seu público.

Além das rodas de leitura, de apreciação e de empréstimo, os mediadores em formação são orientados a desenvolver outras atividades com os públicos com que atuam como: evento de lançamento do projeto; eventos periódicos; saraus; encontro com autores; constituição de grupos de jovens que leem para crianças ou para idosos; visita a bibliotecas, editoras, jornais e feiras de livros etc.

Nas oficinas, os educadores vivenciam as atividades propostas em situações distintas: por exemplo, ora eles se colocam no papel de participantes de uma roda de leitura, mediada pelo formador do grupo, ora eles são desafiados a colocarem-se como mediadores responsáveis pela condução da atividade, tendo como público o coletivo do grupo constituído por seus pares.

Essa duplicidade de experiências lhes permite experimentar e ganhar competência, o que será fundamental para que eles se mobilizem, no sentido de preparar e realizar em seu local de trabalho, com um outro público, as atividades orientadas pelos projetos. Esse movimento incentiva ainda a pesquisa e tende a gerar autonomia e protagonismo, expressos pelas experiências inovadoras que os mediadores realizam ao implementar os projetos. Promove ainda uma revisão das práticas: aquilo que porventura já era realizado passa a ser visto com outro olhar, ganha novos contornos e se amplia. Mesmo quando o participante já tem uma bagagem maior em termos de formação (continuada ou pontual) persiste a avaliação de que a formação realizada pelos projetos organiza, acrescenta, complementa ou traz coisas novas para sua prática. 


\section{5 SENSIBILIZAÇÃO PARA A IMPORTÂNCIA DA LEITURA}

Entre os dados apontados pela pesquisa Retratos da Leitura no Brasil, estão aqueles que dizem respeito ao modo como a leitura é vista socialmente entre os brasileiros: entre as várias alegações para o fato de não ler, $53 \%$ podem ser resumidas em desinteresse, o que, de acordo com Maria Antonieta da Cunha (2007, p.14), configura "um ambiente em que a leitura não é socialmente valorizada, em que o livro não tem um lugar assegurado". Confirmando essa afirmação tem-se o fato de que $86 \%$ dos considerados não-leitores nunca foram presenteados com livros na infância e $55 \%$ nunca viram os pais lendo, informação esta que revela muito sobre as práticas familiares de leitura.

Nesse sentido, o trabalho de formação de mediadores realizado pelos dois projetos passa necessariamente por ações que levam à valorização social da leitura, implícita em seus pressupostos. Já na primeira oficina os participantes são envolvidos em duas atividades que visam sensibilizá-los para a importância da leitura. A primeira delas é a do "baú do tesouro": uma boa quantidade de livros dos mais variados assuntos e gêneros e outros portadores são organizados num cenário em que associa a ideia de ler à de acesso a um tesouro. A reação dos participantes é sempre de encantamento e de surpresa, ainda mais por que são convidados a manusear e ler durante certo espaço de tempo alguns desses livros, revistas e jornais, podendo até levá-los emprestados. Em seguida, os participantes são levados a refletir sobre o porquê de suas escolhas, ou seja, o motivo que os levou a escolher tal obra ou portador em detrimento de outros: o título, a capa, o autor, o tema, o gênero, as ilustrações, etc. Isso lhes dá a medida de quanto esses aspectos podem mobilizar as pessoas, tornando-se muitas vezes fator importante para cativar leitores.

A segunda atividade é o resgate da "história de leitor" dos participantes da formação. Nela, todos são solicitados a recordar e socializar com o grupo seu(s) primeiro(s) contato(s) significativo(s) com a leitura, focalizando o espaço onde isso ocorreu, a possível presença de um mediador, o gênero e o portador. Além da reflexão sobre o papel que esses elementos assumem no processo de formação leitora, a atividade resulta no registro escrito desses percursos pessoais de leitura, posteriormente lançado nos diários de bordo individuais, ou num livro virtual.

Ao longo da formação, as atividades vivenciadas pelos participantes, além de manter essa perspectiva de ampliar o valor simbólico da leitura, permitem 
compreender como se dão os processos de formação leitora, os fatores neles envolvidos, o papel das instituições e as desigualdades sociais que dificultam o acesso à leitura.

\subsection{A IMPORTÂNCIA DO REGISTRO}

Em ambos o projetos, os mediadores são orientados a organizar um "diário de bordo", isto é, um caderno com o registro de tudo que consideram significativo em seu percurso de formação ou de atuação como mediadores de leituras: reflexões, impressões, sínteses, relatos sobre as práticas desenvolvidas, comentários sobre leituras feitas, textos, indicações de leitura, de sites, de atividades culturais, etc.

0 registro, além de possibilitar a reflexão sobre o trabalho realizado e a organização do percurso do mediador, permite retomar, reorientar, avaliar ações desenvolvidas e compartilhar experiências. Sem o registro, perde-se a memória do que ocorreu e a oportunidade de reaplicar ou aprimorar práticas já experimentadas com sucesso ou de evitar a repetição de práticas equivocadas.

\section{7 A FORMAÇÃO E O ACOMPANHAMENTO À IMPLEMENTAÇÃO DO PROJETO}

Nos dois projetos, a formação se realiza por meio de oficinas presenciais de oito horas cada, acrescidas de duas horas não presenciais para a realização de tarefas entre os encontros (estudo, observação e registro de atividades, leituras recomendadas, etc.). Em ambos os projetos, a formação tem a duração de um ano, mas com diferenças na carga horária: no ENR ela é realizada em oito oficinas; no LPS, as oficinas são dezesseis.

A formação é complementada por visitas de acompanhamento, também de caráter formativo. Como não é possível acompanhar todas as instituições envolvidas, as visitas se restringem a quatro no ENR e três no LPS e são realizadas pelo formador do Cenpec, acompanhado do Técnico da Secretaria/ responsável pelo projeto.

Essas visitas fornecem uma amostra de como caminha a implementação dos projetos nas escolas/instituições envolvidas. Permitem observar as atividades de leitura, conversar com o público atendido pelos mediadores em formação, com gestores e outros profissionais da instituição e às vezes com pessoas da comunidade. A partir desse contato é possível orientar ações, fazer recomendações e reconhecer as boas práticas desenvolvidas. 
Aquilo que é observado pelo formador, é socializado nas oficinas: aspectos frágeis orientam recomendações gerais no sentido de superar ou aprimorar as práticas de todo o grupo; as boas práticas são expostas pelo formador ou apresentadas pelo mediador em formação.

Ainda como ação de acompanhamento, são realizadas duas ou mais reuniões de gestão compartilhada com as secretarias dos municípios parceiros. Inicialmente, essas reuniões têm como objetivo negociar aspectos relativos à realização da parceria, organização da(s) turma(s) de profissionais beneficiados, infraestrutura necessária, contrapartidas etc. Após o início da formação, essas reuniões passam a ter como foco informações sobre o andamento da implementação, as conquistas e as dificuldades encontradas. 0 objetivo é que a reflexão conjunta dos parceiros resulte em intervenções eficazes. Ao final da parceria, é feita uma avaliação e, a partir dos resultados obtidos, são feitas recomendações e discutidas as perspectivas de continuidade dos projetos.

É comum ocorrerem nos municípios atendidos ações vinculadas direta ou indiretamente à implementação dos projetos e transformadas em políticas públicas, como: a aquisição/ampliação de acervos; a formação parcial ou total dos profissionais da rede, referenciada nas propostas dos projetos e realizada pelas próprias secretarias municipais de educação; o incentivo a projetos de leitura nas escolas; a articulação com outras secretarias (principalmente a de Cultura) para a promoção da leitura em outros espaços; a criação/ revitalização de bibliotecas escolares e públicas e a institucionalização de eventos voltados à leitura.

\section{CIRCUNSTÂNCIAS QUE DIFICULTAM A IMPLEMENTAÇÃO DOS PROJETOS}

Ao longo do desenvolvimento dos projetos surgem, como esperado, circunstâncias que dificultam sua implementação e acabam por interferir no alcance das metas estabelecidas. Por vezes, elas decorrem de ações equivocadas, de aspectos infraestruturais e são passiveis de solução em função de orientações aos profissionais em formação e de conversas e ajustes com as secretarias parceiras. Outras vezes, elas estão relacionadas a questões estruturais, de gestão das secretarias ou das escolas ou ainda a questões pessoais e profissionais envolvendo os mediadores em formação. Nesse caso, a superação dos obstáculos costuma ser bem mais difícil, porque a solução muitas vezes está fora da área de atuação da equipe do Cenpec e também dos técnicos que acompanham os educadores e que são nossos interlocutores junto ao poder público. 
Elencamos, a seguir alguns desses aspectos dificultadores que, segundo a experiência dos projetos, mais afetam o trabalho de formação de mediadores e sua atuação na formação de outros leitores:

- Falta de intimidade dos profissionais com a leitura de maneira geral, seja de obras literárias, de não ficção, de periódicos etc. Em função disso, a primeira tarefa dos projetos é aproximá-los da leitura e, em especial, da literatura, tornando-os leitores mais assíduos e experientes. Não nos estenderemos aqui na busca das causas desse problema, mas inúmeras pesquisas têm revelado que grande parte dos profissionais da educação, por exemplo, são oriundos de extratos sociais em que pais e avós são analfabetos ou têm baixa escolaridade, sendo eles a primeira geração a atingir o curso superior. Nesse sentido, tiveram, provavelmente, seus primeiros contatos com livros ao ingressar na escola, ou mais tardiamente. Como complicador dessa situação, grande parte desses profissionais passa por uma formação inicial bastante deficiente, tendo pouco contato com a leitura ou não sendo incentivados a ler espontaneamente.

- Falta de acervos para realizar as atividades propostas, sobretudo o empréstimo. Essa é uma realidade bastante comum nas escolas públicas, encontrada em boa parte dos municípios atendidos pelos projetos. Apesar da iniciativa do governo federal, de encaminhar às escolas acervos de boa qualidade, o que se encontra circulando no espaço escolar são frequentemente acervos insuficientes, com pouca diversidade e, às vezes, de baixa qualidade. A proposta dos projetos é que as escolas possam se tornar polos de irradiação de leitura, o que significa ter acervos diversificados, de qualidade e, sobretudo, acessíveis a alunos, profissionais da escola e pais.

Quando os acervos são um pouco maiores, muitas escolas criam estratégias para envolver os pais e familiares no processo de formação leitora dos alunos. Encaminham livros em sacolas para que os familiares leiam para e com as crianças e registrem num caderno observações a respeito desse momento. Às vezes, essas ações são ampliadas com a inclusão, nas sacolas, de livros, revistas e outros portadores direcionados para os pais e familiares.

As doações de acervos pelas fundações empresariais financiadoras dos projetos, mais do que amenizar uma situação de carência de livros nas escolas públicas, funcionam como um estímulo ao poder público no sentido de investir na aquisição e distribuição de materiais de leitura para as escolas da rede. 
- A falta de espaços destinados à leitura dentro das escolas também é um fator importante nesse rol de dificuldades que interferem na consecução de um projeto de formação leitora. As escolas, frequentemente, não possuem salas de leitura ou bibliotecas, nas quais os alunos possam realizar leitura livre, consulta a obras de referência, empréstimos ou mesmo estar com seus professores numa roda de leitura ou de apreciação. Muitas vezes esses espaços são improvisados e outras vezes desarticulados e desfeitos, quando a demanda escolar exige a abertura de mais salas de aula.

Quando o espaço de leitura inexiste, as escolas buscam soluções para além dos cantinhos de leitura, bastante comuns nas salas de aula: os livros acabam circulando em caixas, baús, carrinhos de supermercado, etc.

- Concretização efetiva de um trabalho coletivo dentro das escolas. Uma das formas de viabilizar esse trabalho é garantir, dentro da carga horária paga ao professor, momentos em que possa se reunir com seus pares, sob a orientação de um coordenador pedagógico, para estudar, discutir, refletir e definir aspectos pedagógicos ligados ao ensino e à aprendizagem. Esses horários de trabalho pedagógico coletivo podem ser destinados à disseminação dos projetos, ao compartilhamento de experiências ligadas à leitura e às atividades desenvolvidas pelos educadores para a formação de alunos leitores etc.

Efetivamente, grande parte das escolas envolvidas nas formações do ENR e do LPS utilizam os horários de trabalho coletivo para levar as propostas dos projetos ao corpo docente como um todo. Todavia, a frequência e a quantidade de horas estabelecidas pelas secretarias municipais de educação variam bastante e quase sempre são insuficientes para garantir um aprofundamento do trabalho com leitura. Ainda mais que parte do tempo desses encontros é muitas vezes utilizado para informes e realização de tarefas burocráticas.

Para além dessa questão, é importante ressaltar que o apoio da equipe gestora das escolas aos professores envolvidos na implementação dos projetos contribui grandemente para o sucesso das ações e para sua disseminação no espaço escolar. Nesse caso, cabe à direção e à coordenação oferecer condições para que as boas práticas sejam incorporadas à rotina da escola. Isso significa: incentivar o comparecimento e a participação dos educadores inscritos nas oficinas dos projetos; estimulá-los para que ponham em prática e socializem o que aprenderam; fazer circular os acervos existentes na escola; disponibilizar recursos necessários à realização das rodas de leitura e outras atividades; estimular e apoiar a realização de atividades de leitura com a comunidade, dentro e fora da escola; acompanhar as atividades de leitura realizadas; integrar o ENR ou o LPS ao projeto político-pedagógico da escola; 
buscar parcerias com bibliotecas públicas e outras instituições para disseminar o gosto pela leitura, avaliar com todos os envolvidos tanto o processo como os resultados obtidos com a implementação das propostas.

Quanto mais essas recomendações são acatadas e postas em prática, maior a possibilidade de se conseguir sucesso, solidez e permanência do trabalho desenvolvido.

Assim como ocorre na esfera escolar, a clareza de objetivos, a articulação entre a secretaria de educação e suas escolas, o apoio e incentivo à implementação dos projetos e às iniciativas autônomas deles decorrentes, e o acompanhamento das ações realizadas, interferem nos resultados obtidos.

Exemplos disso são municípios como Ribeirão Preto, parceiro do ENR em 2005 e 2006, que mobilizou intensamente sua rede em torno das ações de leitura, incentivando as escolas a postarem na Comunidade Virtual do Território Escola relatos de prática e fotos das atividades realizadas. 0 município mantém até hoje o ENR entre os projetos de formação da SME. Mais recentemente, exemplos como o de Juquitiba, que vem oferecendo, desde 2010, formação a todos os professores da rede; Francisco Morato, que, desde 2010, integrou o ENR a outras ações voltadas para a leitura e promovidas pela SME; e São Bernardo do Campo, onde o ENR tem colaborado para efetivar a parceria da Secretaria de Cultura com outras secretarias, formando agentes de saúde, funcionários dos serviços urbanos e representantes de associações de moradores da periferia, com o objetivo de levar a leitura a outros espaços e públicos.

No LPS exemplos de bons resultados decorrentes do trabalho articulado entre SMEs e suas redes também são comprovados em municípios como Campina Grande, Ingá, Alagoa Nova, Mogeiro, Guarabira, Serra Redonda, Apiaí e Itaoca. Para isso contribui a premiação que encerra o ciclo de formações, funcionando como um incentivo a mais para o trabalho conjunto das secretarias e escolas, na medida em que reconhece as boas práticas desenvolvidas pelos municípios em relação à leitura. Técnicos, gestores e educadores, por orientação do projeto, planejam, executam e registram ações de leitura realizadas com alunos e com a comunidade. Planos de ação das secretarias, registros de atividades desenvolvidas pelo coletivo das escolas e relatos de prática produzidos por professores são produtos que constituem categorias dessa premiação. 


\section{FORMATION OF READING MEDIATORS: SYSTEMIZATION OF TWO EXPERIENCES}

\section{ABSTRACT}

This paper seeks to systematize the experience and methodology behind two projects for training reading mediators carried out by Cenpec. These projects were developed at different times and are the products of different demands, maintaining their own growth experiences and characteristics; yet, they both part from a common methodological system. In order to contribute to a comparison of the relationship of these methodological aspects and the results reached by the projects, the context in which they are situated is presented along with a background of their past experiences, the theoretical assumptions that guided them, the strategies that have contributed to achievement of goals, and their main challenges.

KEYWORDS:

Continuing education. Reading mediation. Mediation training methodology. Teaching readers. 


\section{Referências}

BAKHTIN, Mikhail (V. N. Volochinov). Marxismo e filosofia da linguagem. São Paulo: Hucitec,1990.

BAKHTIN, Mikhail. Estética da criação verbal. São Paulo: Martins Fontes,1992.

CUNHA, Maria Antonieta da. Acesso à leitura no Brasil: considerações a partir da pesquisa. In: Retratos da Leitura no Brasil. São Paulo: Instituto Pró- Livro: 2007. Disponível em http://www.prolivro.org.br/ipl/publier4.0/dados/ anexos/48.pdf. Acesso em 13/11/2011.

INAF. Indicador Nacional de Alfabetismo Funcional: principais resultados; 2009. São Paulo: Instituto Paulo Montenegro; Ação Educativa. Disponível em http://www.ipm.org.br/download/inaf_brasil2009_relatorio_divulgacao_ final.pdf. Acesso em 13/11/ 2011.

RETRATOS DA LEITURA NO BRASIL. São Paulo: Instituto Pró- Livro: 2007. Disponível em http://www.prolivro.org.br/ipl/publier4.0/dados/anexos/48. pdf. Acesso em 13/11/2011.

VYGOTSKY, Lev Semenovich. A formação social da mente. São Paulo: Martins Fontes, 1991.

Recebido em: NOVEMBRO de 2011

Aprovado em: DEZEMBRO de 2011 